\title{
NELSON GOODMAN: SOBRE A NATUREZA DA EXPERIÊNCIA ESTÉTICA
}

\author{
Nelson Goodman: on the nature of aesthetics experience
}

\author{
Juliano Santos do Carmo *
}

Resumo: O presente trabalho visa apresentar o caráter cognitivo da experiência estética a partir da perspectiva de Nelson Goodman exposta em Linguagens da Arte (1976). Tradicionalmente a arte tem sido considerada como necessariamente subjetiva e radicalmente contraposta aos modelos científicos de descrição e explicação da realidade. Goodman apresenta uma nova e instigante maneira de conceber a experiência estética em que as artes, assim como a ciência, descrevem modelos de realidade. Vou procurar mostrar que o modelo de Goodman é suficientemente capaz de figurar como uma alternativa razoável às tendências fortemente reducionistas de naturalização da experiência estética na filosofia contemporânea, ao mesmo tempo em que procurarei ressaltar o potencial de sua posição em reestabelecer a conexão entre arte e estética.

Palavras-Chave: Nelson Goodman, Estética, Naturalismo.

\begin{abstract}
This work aims to present the cognitive character of aesthetic experience from the perspective of Nelson Goodman exposed in Languages of Art (1976). Traditionally, the art has been regarded as necessarily subjective and radically opposed to scientific models of description and explanation of reality. Goodman presents a new and exciting way of conceiving the aesthetic experience, in which the arts as well as science, describe models of reality. I will seek to show that the Goodman model is able to be a reasonable alternative to the heavily reductionist tendencies naturalization of aesthetic experience in contemporary philosophy. At the same time I will try to highlight the potential of his position to reestablish the connection between art and aesthetics.
\end{abstract}

Key-Words: Nelson Goodman, Aesthetics, Naturalism.

\footnotetext{
* Professor adjunto do Departamento de Filosofia da Universidade Federal de Pelotas. juliano.ufpel@gmail.com
}

\begin{tabular}{|c|c|c|c|c|c|}
\hline intuitio & $\begin{array}{c}\text { ISSN } \\
1983-4012\end{array}$ & Porto Alegre & Vol.8 $-\mathrm{N}^{\circ} .1$ & $\begin{array}{c}\text { Junho } \\
2015\end{array}$ & p.04-14 \\
\hline
\end{tabular}




\section{Introdução}

A experiência estética já foi definida como uma espécie de contemplação passiva ou mesmo como uma espécie de apreensão direta ou imediata, enquanto a arte já foi definida algumas vezes como simulacro, uma cópia degenerada do "mundo das ideias" (modelo platônico), e outras vezes como mimese, uma imitação da natureza (modelo aristotélico). Apesar dos "defeitos filosóficos e absurdos estéticos óbvios"1 destes modelos, alguns filósofos ainda procuram encontrar uma representação de mundo imaculada, onde a arte seja completamente livre de qualquer conceitualização e absolutamente dispensada de todas as suas funções cognitivas ${ }^{2}$, contribuindo assim para a ampliação do abismo aparentemente intransponível entre estética e arte ${ }^{3}$. O objetivo geral deste trabalho é apresentar um modelo filosófico de estética que surgiu em meados da década de 1970 e que tem sido desenvolvido como uma espécie de antídoto às tendências fortemente reducionistas de naturalização da experiência estética. Trata-se, mais especificamente, da abordagem de Nelson Goodman em Linguagens da Arte (1976). Além de fornecer subsídios para repensar a relação desgastada entre estética e arte, a posição de Goodman também tem o potencial de lançar luz sobre os aspectos cognitivos da arte. Antes, contudo, de explicitar o potencial da posição de Goodman, convém explicar o que se entende por "estética naturalizada" e os motivos pelos quais se acredita que a posição de Goodman pode ser considerada como um modelo não-reducionista.

\section{A Estética Naturalizada}

\footnotetext{
${ }^{1}$ GOODMAN, N. Linguagens da Arte. Lisboa: Gradiva, 2006, p. 256.
}

${ }^{2}$ É difícil notar em primeira instância em que sentido a arte é uma atividade cognitiva, pois tradicionalmente é possível identificar a cognição com (i) o que comumente chamamos de conhecimento proposicional; ou (ii) como algo essencialmente ligado às nossas capacidades cognitivas; ou (iii) como algo que diz respeito ao conteúdo do conhecimento; ou, finalmente, (iv) à natureza de nossos processos mentais que nos permitem ter acesso e utilizar o conhecimento. A posição de Goodman, como veremos, será fomentada pela ideia de que não existem diferenças substanciais entre arte e ciência.

${ }^{3}$ Teóricos e artistas da arte moderna, inspirados na estética de Hegel (Marcel Duchamp, por exemplo), procuraram reinscrever a fruição estética através do deslocamento do eixo de investigação centrado na "arte do olho" para um modelo de estética que privilegiava a "experiência mental". A arte não é mais apenas uma questão de "sensação", mas, sobretudo, uma questão de "cognição". O modelo da contemplação passiva é substituído por um modelo onde a experiência estética é ativa, inquieta e questionadora. Apesar da amplitude e variedade característica das discussões contemporâneas sobre estética, nem sempre é óbvia a necessidade de separar radicalmente os domínios da estética e da arte.

\begin{tabular}{|c|c|c|c|c|c|}
\hline intuitio & $\begin{array}{c}\text { ISSN } \\
1983-4012\end{array}$ & Porto Alegre & Vol.8 $-\mathrm{N}^{\circ} .1$ & $\begin{array}{c}\text { Junho } \\
2015\end{array}$ & p.04-14 \\
\hline
\end{tabular}


O Nelson Goodman: sobre a natureza da experiência estética

A naturalização da estética é uma parte importante da ampla agenda de discussões contemporâneas sobre a "naturalização do conhecimento"*4. A ciência tem possibilitado a observação de fenômenos cognitivos através das interfaces de visualização computadorizadas (como, por exemplo, o córtex, os processos celulares, etc.) e isso tem contribuído de forma decisiva para o rearranjo de diversos campos de investigação, cujo objetivo central é encontrar uma propriedade fisiológica (natural) para alguns fenômenos do conhecimento humano. Essa tendência pode ser percebida na crescente interação de filósofos, artistas e teóricos da arte com neurocientistas. Basta observar o surgimento das recentes subáreas de investigação: a Neurofilosofia e a Neuroarte.

As teorias naturalistas podem ser subdivididas em teorias reducionistas e não-reducionistas. As teorias reducionistas visam explicar redutivamente a natureza da experiência estética como necessariamente vinculada aos processos cerebrais complexos. Diversos neurocientistas (Zeki, Bartels, Cela-Conde et al.), por exemplo, têm procurado mostrar, através do uso dos mais recentes desenvolvimentos tecnológicos de neuroimageamento ou de magnetoencefalografia, que o córtex préfrontal desempenha um papel fundamental em nossa percepção estética visual ${ }^{5}$. Andreas Bartels e Zemir Seki também procuraram mostrar que o cérebro visual é composto por diversos sistemas de processamento de múltiplos estágios paralelos, onde cada um seria responsável por uma tarefa (tais como perceber cores ou movimentos, por exemplo) ${ }^{6}$.

Existem muitos aspectos problemáticos nas posições reducionistas sobre a experiência estética, sobretudo no que diz respeito aos processos amplamente complexos envolvidos no estudo experimental da estética. Ainda que houvesse uma espécie de "elemento comum" presente em toda a experiência estética e compartilhado por todos os seres humanos, seria muito difícil explicar os vários fatores que afetam os critérios estéticos (sociais, culturais, históricos, biológicos, etc.), pois tais critérios poderiam, potencialmente, produzir uma verdadeira dispersão dos resultados experimentais na pesquisa sobre a percepção estética visual ${ }^{7}$.

\footnotetext{
${ }^{4}$ A principal característica da posição filosófica amplamente conhecida como "Naturalismo" é justamente a tentativa de fundamentar a epistemologia, a moral, a linguagem e a estética em propriedades naturais (submetidas ou sujeitas às leis do mundo natural). Neste sentido, o naturalismo é uma espécie de reação contrária aos modelos filosóficos que pressupõem a existência de qualquer propriedade que não esteja sujeita aos processos e eventos do mundo natural. Qualquer intervenção ou reafirmação de elementos "sobrenaturais" (vale dizer: "propriedades fundacionais autoevidentes", "propriedades necessárias que existem por si mesmas", etc.) é completamente ilusória e desnecessária.

${ }^{5}$ A percepção estética visual é definida como a capacidade de perceber visualmente um atributo adicionado a outras características dos objetos (tais como a forma, a cor e o movimento), e que é uma capacidade especificamente humana que foi supostamente fixada durante a evolução biológica. Ver: CELA-CONDE, C. Activation of the prefontral cortex in the human visual aesthetic perception. New York: PNAS, 2004.

${ }^{6}$ ZEKI, S. Inner Vision: An Exploration of Art and the Brain. Oxford: Oxford University Press, 1999.

${ }^{7}$ CELA-CONDE, C. Activation of the prefontral cortex in the human visual aesthetic perception. New York: PNAS,
}

\begin{tabular}{|c|c|c|c|c|c|}
\hline intuitio & $\begin{array}{c}\text { ISSN } \\
1983-4012\end{array}$ & Porto Alegre & Vol.8 $-\mathrm{N}^{\circ} .1$ & $\begin{array}{c}\text { Junho } \\
2015\end{array}$ & p.04-14 \\
\hline
\end{tabular}


As teorias naturalistas não-reducionistas, por outro lado, procuram explicar a natureza da experiência estética como necessariamente vinculadas aos nossos hábitos linguísticos e ao uso de sistemas simbólicos. Aqui é possível elencar diversas posições teóricas distintas (tanto quanto a elasticidade do termo "naturalismo" possa permitir), desde o anti-intelectualismo de Gilbert Ryle e Wittgenstein, como o cognitivismo nominalista de Nelson Goodman. De qualquer modo, em ambos os modelos de "naturalismos" é possível observar uma cisão importante entre teorias cognitivistas e não-cognitivistas no que respeita a explicação da natureza da experiência estética. O que nos autoriza a classificar ambos os grupos como "naturalistas" é o abandono de pressupostos substancializados ou "sobrenaturais" que permeavam as discussões filosóficas clássicas (no caso específico da estética, a recusa das ideias substancializadas de "beleza", "sublime", "gosto", etc.).

\section{O Uso de Sistemas Simbólicos}

Em Linguagens da Arte (1976), Nelson Goodman defendeu um modelo "construtivista" que é suficientemente capaz de se estabelecer como alternativa aos modelos reducionistas de estética. A estratégia de Goodman foi retomada três anos depois em Fato, Ficção e Previsão (1979), onde põe em cheque um aspecto central da investigação científica, a saber: a impotência do método indutivo para gerar verdades imutáveis. O "novo enigma da indução" (que retomou e atualizou a posição de David Hume) denunciou a completa inexistência de verdades absolutas e ideias inatas. As coisas, os fatos, as relações de causalidade e as próprias regularidades observadas na natureza, são construções humanas.

O construtivismo de Goodman também é explicitamente um tipo de nominalismo ${ }^{8}$, pois defende que não existem entidades abstratas por si mesmas ("belo", "beleza”, etc.). A universalidade é tratada como ilusória, pois sendo o fruto da observação de certas regularidades passadas, não é, portanto, confirmada pela experiência atual e nem possui qualquer relação de necessidade lógica. A multiplicidade de posições (ou de sistemas simbólicos) parece ser a única possibilidade real. Há diversos teóricos e artistas que assumem posições semelhantes ${ }^{9}$. Segundo Anne Cauquelin, por exemplo, uma das ideias

2004.

${ }^{8}$ Ver: CAUQUELIN, Anne. Arte Contemporânea: Uma Introdução. São Paulo: Martins Fontes, 2005.

${ }^{9}$ Apesar de não possuir vínculos diretos com os movimentos de vanguarda da arte russa do início do século XX, com Malevich e Rodchenko, o construtivismo de Goodman compartilha alguns de seus pressupostos básicos, em especial a negação completa da ideia de "arte pura" nascida de um ato de pura criação humana. Vale lembrar que o construtivismo na arte russa, com o uso de cores puras e a simplificação das formas, contribuiu de modo decisivo para um modo de produção de objetos em série e para a reprodução industrial. Ao mesmo tempo os artistas passaram a utilizar a ideia de objeto para reportar-se ao modo de produção industrial, negando assim a noção de "atelier" que estava intimamente associada ao modelo de "belas artes".

\begin{tabular}{|c|c|l|l|l|l|}
\hline intuitio & $\begin{array}{c}\text { ISSN } \\
1983-4012\end{array}$ & Porto Alegre & Vol.8 $-\mathrm{N}^{\mathrm{o}} .1$ & $\begin{array}{c}\text { Junho } \\
2015\end{array}$ & p.04-14 \\
\hline
\end{tabular}


centrais de Marcel Duchamp era de que "a arte é um sistema de signos, e a realidade desvelada por meio deles é construída pela linguagem, seu motor determinante" ${ }^{\prime 10}$.

Ao constatar que a inspeção sensorial de quaisquer grupos de objetos não fornece um critério objetivo para classificá-los como pertencentes a uma mesma categoria, Goodman ressaltou a importância de nossos sistemas simbólicos ("sistemas de referência", ou "pano de fundo conceitual" poderiam ser tomados como sinônimos aqui). O único modo de distinguir suficientemente as características que contam daquelas que não contam na hora de classificar objetos em uma mesma categoria é através de um "background"11, de um sistema conceitual. Tudo o que fazemos é organizar e classificar objetos através de regras convencionais instituídas e proliferadas para contar como uma classificação. Para acentuar ainda mais o construtivismo de Goodman, é importante notar que até mesmo as nossas regras de inferência e validade dedutiva ou indutiva não são confirmadas pela realidade, mas, antes, são válidas ou inválidas em virtude de regras gerais construídas para contar como a validade dedutiva ou indutiva.

Como veremos mais tarde, Goodman assume uma postura bastante peculiar em relação à noção de verdade, pois toma a verdade como uma instância do critério de correção. Uma peculiaridade da noção de "correção" é justamente o fato de que ela funciona como uma espécie de critério de aceitabilidade geral para os mais diferentes sistemas simbólicos (teorias científicas, posições filosóficas, movimentos artísticos, religiões e sistemas de crenças em geral). Cada sistema simbólico possui sua própria gramática (sua estrutura sintática e semântica), a qual determina as formas de referência do sistema (denotação, exemplificação, representação, expressão, descrição, etc.) e também o que deve ocorrer para que o sistema simbólico como um todo possa ser considerado "correto".

É importante ressaltar que Goodman distingue três tipos de sistemas simbólicos: (i) os sistemas representacionais (sintática e semanticamente densos); (ii) os sistemas linguísticos (sintaticamente diferenciados e semanticamente densos); e (iii) os sistemas notacionais (sintática e semanticamente diferenciados) $)^{12}$. Os três tipos de sistemas simbólicos supostamente classificam e organizam todas as nossas atividades convencionais e todos os nossos modelos de realidade (ou visões de mundo). Os quatro principais "sintomas do estético" elencados por Goodman são justamente a "densidade sintática", a "densidade semântica", a "plenitude sintática" e a "exemplificação" conjuntamente suficientes e disjuntamente necessários para a experiência estética.

${ }^{10}$ GOODMAN, N. Linguagens da Arte. Lisboa: Gradiva, 2006, p. 90.

${ }^{11}$ SEARLE, J. Consciência e Linguagem. São Paulo: Martins Fontes, 2010.

${ }^{12}$ GOODMAN, N. Linguagens da Arte. Lisboa: Gradiva, 2006, p. 241-255.

${ }^{13}$ GOODMAN, N. Linguagens da Arte. Lisboa: Gradiva, 2006, p. 266.

\begin{tabular}{|c|c|c|c|c|c|}
\hline intuitio & $\begin{array}{c}\text { ISSN } \\
1983-4012\end{array}$ & Porto Alegre & Vol.8 $-\mathrm{N}^{\circ} .1$ & $\begin{array}{c}\text { Junho } \\
2015\end{array}$ & p.04-14 \\
\hline
\end{tabular}


A arte e a ciência não estão completamente separadas, pois a experiência estética é concebida como algo que nos ajuda a fortalecer nossos "músculos intelectuais". A arte, diz Goodman, "prepara-nos para sobreviver, conquistar e ganhar. E canaliza a energia em excesso, afastando-a de escapes destrutivos. Torna o cientista mais perspicaz, o mercador mais astuto e tira os delinquentes juvenis das ruas"14.

Neste sentido, tanto o artista, como o filósofo ou o cientista, constroem modelos de realidade, e os modelos são viáveis ou não unicamente em função do objetivo para o qual foram projetados ${ }^{15}$. $\mathrm{O}$ critério de correção para cada modelo de realidade é interno ao próprio sistema simbólico ao qual ele pertence, é por isso que o critério de correção (ou adequação) depende das convenções adotadas para o próprio modelo. Neste sentido, as artes desenvolvem modelos de realidade cuja correção depende unicamente de um conjunto de convenções proliferadas pela própria tradição.

Este insight já aparecia em alguns movimentos artísticos do século XX, os quais pensaram a experiência estética como uma espécie de construção humana permeada de convenções. Para a vanguarda russa, por exemplo, a construção da arte se dá pelo processo de politização da arte; para outros modelos a construção se dá de modo mais especializado, como uma espécie de expansão de nosso conhecimento a respeito do mundo. Alguns teóricos inspirados na filosofia tardia de Wittgenstein defendiam que conteúdo intencional do artista deve ser publicamente acessível, a intenção não pode ser um processo mental interno, pois do contrário ela seria radicalmente privada.

Neste sentido, é preciso conceber o conteúdo intencional de uma obra de arte como necessariamente desvinculada de processos internos. Os primeiros ready-mades de Duchamp, A Roda de Bicicleta (1913) e A Fonte (1917), já apontavam para esta direção. Apenas os signos, ou ainda o sistema de indicadores, delimitam os locais da arte. Ao expor objetos "prontos", já existentes e em geral utilizados na vida cotidiana, como a bicicleta ou o mictório batizado de "fonte", Duchamp revela que apenas o local da exposição torna tais objetos "obras de arte".

Em outras palavras, a arte é definida única e exclusivamente pelo sistema simbólico ao qual ela está inserida, e é isso que Joseph Kosuth ${ }^{16}$ parece ter em mente quando afirma que a arte é análoga a uma "proposição analítica", pois o critério de correção (verificação) se dá unicamente dentro do contexto da

\footnotetext{
${ }^{14}$ GOODMAN, N. Linguagens da Arte. Lisboa: Gradiva, 2006, p. 269-70.

15 “Apesar de não haver qualquer critério exterior de verdade, Goodman não aceita, contudo, o tipo de relativismo segundo o qual tudo vale e tudo se equivale, pois defende que há um critério geral de aceitabilidade para as diferentes versões de mundos. Esse critério é a correção, sendo a verdade apenas um caso particular do critério de correção. A noção de correção tanto se aplica a teorias científicas, como a pinturas, esculturas (abstratas ou figurativas), a peças musicais e aos juízos morais, assim como a qualquer tipo de símbolo. Neste aspecto, a arte, a ciência e o senso comum encontram-se exatamente no mesmo plano". Ver: ALMEIDA, A. Introdução à tradução Portuguesa. In. GOODMAN, N. Linguagens da Arte. Lisboa: Gradiva, 2006.

${ }^{16}$ KOSUTH, J. A Arte Depois da Filosofia. In: Escritos de Artistas. Rio de Janeiro: Jorge Zahar Editor, 2006.
}

\begin{tabular}{|c|c|c|c|c|c|}
\hline intuitio & $\begin{array}{c}\text { ISSN } \\
1983-4012\end{array}$ & Porto Alegre & Vol.8 $-\mathrm{N}^{\circ} .1$ & $\begin{array}{c}\text { Junho } \\
2015\end{array}$ & p.04-14 \\
\hline
\end{tabular}


própria arte. A história da arte possibilita a construção de novas proposições, mas é impossível construir novas proposições de modo completamente isolado (de modo alheio ao sistema conceitual). Kosuth afasta-se do modelo de Goodman, contudo, quando pensa que a obra de arte não "diz" nada a respeito do mundo.

\section{O Papel Cognitivo da Arte}

Segundo Goodman, a arte é indispensável para a aquisição de conhecimentos, pois na medida em que constrói modelos de realidade, ela expande nosso conhecimento sobre o mundo. É importante notar, como mencionei no parágrafo anterior, que essa suposição vai de encontro ao que Joseph Kosuth defendia em A Arte Depois da Filosofia (2006), onde este afirmava explicitamente que a arte é uma espécie de "proposição analítica" e que, como tal, é incapaz de expandir nosso conhecimento.

É necessário separar a arte da estética, porque a estética se refere a opiniões sobre a percepção do mundo em geral. No passado uma das duas principais funções da arte era o seu valor decorativo. De modo que qualquer ramo da filosofia que se referisse à "beleza" e, portanto, ao gosto, estava inevitavelmente obrigado a falar também sobre arte. Deste "hábito" surgiu a noção de que existia uma conexão conceitual entre arte e a estética, a qual não é verdadeira ${ }^{17}$.

Ao que parece a separação radical defendida por Kosuth entre arte e estética é semelhante em essência àquela defendida pelos filósofos do Círculo de Viena entre juízos analíticos e juízos sintéticos. A opinião de Kosuth é fortemente rechaçada na medida em que Goodman, seguindo Quine e Putnam ${ }^{18}$, também abandona a dicotomia analítico-sintético, uma vez que tanto o juízo analítico quanto o juízo sintético representam processos puramente conceituais. A arte, assim como a linguagem, faz parte de um sistema simbólico que possui sua própria "gramática".

Uma tradição persistente retrata a atitude estética como uma contemplação passiva do imediatamente dado, uma apreensão direta do que é apresentado, não contaminada por qualquer conceptualização, isolada de todos os ecos do passado e todas as ameaças e promessas do futuro, dispensada de todos os seus afazeres [...]. Defendi, pelo contrário, que temos de ler a pintura tão bem quanto o poema e que a experiência estética é dinâmica e não estática. Envolve a discriminação delicada e o discernimento de relações sutis, a identificação do sistema de símbolos e de caracteres nesses sistemas e o que esses caracteres denotam e exemplificam, interpretar obras e reorganizar o mundo em termos das obras e as obras em termos do mundo ${ }^{19}$.

\footnotetext{
${ }^{17}$ KOSUTH, J. A Arte Depois da Filosofia. In: Escritos de Artistas. Rio de Janeiro: Jorge Zahar Editor, 2006, p. 02. ${ }^{18}$ Ver: QUINE, W.V. The Two Dogmas of Empiricism. New York: The Philosophical Review 60, 1951 (20-43). PUTNAM, H. The Colapse of the Fact/Value Dichotomy and Others Essays. New York: Harvard University Press, 2004.

${ }^{19}$ GOODMAN, N. Linguagens da Arte. Lisboa: Gradiva, 2006, p. 255-6.
}

\begin{tabular}{|c|c|l|l|l|l|}
\hline intuitio & $\begin{array}{c}\text { ISSN } \\
1983-4012\end{array}$ & Porto Alegre & Vol.8 $-\mathrm{N}^{\circ} .1$ & $\begin{array}{c}\text { Junho } \\
2015\end{array}$ & p.04-14 \\
\hline
\end{tabular}


Goodman pergunta pelas características que diferenciam propriamente a atividade estética de outros comportamentos inteligentes "como a percepção, a conduta corrente e a investigação científica", e procura mostrar que se a ciência procura o conhecimento sem se preocupar com fins práticos, "ocupandose da previsão enquanto teste da verdade, e não enquanto guia do comportamento, então a investigação 'desinteressada' compreende simultaneamente a experiência científica e a estética"20. Goodman irá concluir que não existe uma diferença substancial entre o estético e o científico ${ }^{21}$.

Sugeri anteriormente que a maior parte dos problemas que nos tem vindo a assolar são culpa da dicotomia tirânica entre o cognitivo e o emotivo. Num lado colocamos a sensação, a percepção, a inferência, a conjectura, toda a inspeção e investigação fria, fato e verdade; no outro colocamos o prazer, a dor, o interesse, a satisfação, o desapontamento, toda a resposta afetiva tonta, gostar e detestar. De uma forma muitíssimo eficiente, isso impede-nos de ver que na experiência estética as emoções funcionam cognitivamente ${ }^{22}$.

As emoções funcionam cognitivamente, como diz Goodman, na exata medida em que ao invés de privar a experiência estética de emoções, é a compreensão que está a ser enriquecidas por elas. "O uso cognitivo envolve discriminar e relacionar emoções para aferir e apreender a obra, e para a integrar no resto da nossa experiência do mundo" ${ }^{\text {23 }}$. A ideia é a de que as experiências sensoriais e emotivas se relacionam de modo complexo com as propriedades dos objetos, sendo que o uso cognitivo da emoção não é algo isolado de outros modos de conhecer. Se a experiência estética envolve emoções e emoções possuem uma função cognitiva, então a experiência estética não está necessariamente desvinculada da cognição. Além disso, o uso cognitivo das emoções não é uma exclusividade da experiência estética, pois ele também está presente em algumas experiências não-estéticas. O cognitivo, apesar de frequentemente contrastar tanto com o prático como com o passivo, não exclui o sensorial ou o emotivo. Isto é, o que podemos conhecer através das artes é conhecido tanto sensivelmente como racionalmente.

Assim como nos sistemas simbólicos das linguagens naturais os símbolos são os meios de comunicação, nos sistemas simbólicos das artes as obras de arte comunicam fatos, pensamentos e sentimentos.

A simbolização é, pois, avaliada em função de como serve ao propósito cognitivo: pela sutileza das suas distinções e pela justeza das suas alusões; pelo modo como apreende, explora e dá forma ao mundo; pelo modo como analisa, categoriza, ordena e organiza; pelo modo como participa na produção, manipulação, retenção e transformação do conhecimento. Considerações de simplicidade e sutileza, poder e precisão, âmbito e seletividade, familiaridade e inovação são igualmente relevantes, rivalizando

\footnotetext{
${ }^{20}$ GOODMAN, N. Linguagens da Arte. Lisboa: Gradiva, 2006, p. 256-7.

${ }^{21}$ GOODMAN, N. Linguagens da Arte. Lisboa: Gradiva, 2006, p. 259.

${ }^{22}$ GOODMAN, N. Linguagens da Arte. Lisboa: Gradiva, 2006, p. 262.

${ }^{23}$ GOODMAN, N. Linguagens da Arte. Lisboa: Gradiva, 2006, p. 262.
}

\begin{tabular}{|c|c|c|c|c|c|}
\hline intuitio & $\begin{array}{c}\text { ISSN } \\
1983-4012\end{array}$ & Porto Alegre & Vol.8 $-\mathrm{N}^{\circ} .1$ & $\begin{array}{c}\text { Junho } \\
2015\end{array}$ & p.04-14 \\
\hline
\end{tabular}


frequentemente entre si; o seu peso é relativo aos nossos interesses, informação e investigação ${ }^{24}$.

Desse modo, a experiência estética é também um tipo de experiência cognitiva, a qual é avaliada em termos de seus padrões de eficácia cognitiva. Ainda que frequentemente os termos "verdade/falsidade" sejam reservados para proposições científicas, não é de todo claro que os termos "verdade/falsidade" não sejam meros substitutos para os termos "adequação/inadequação" ou mesmo "correção/incorreção". Se não houver uma diferença substancial entre o verdadeiro e o correto/adequado, então as diferenças entre arte e ciência diminuem consideravelmente e as afinidades entre ambos os domínios se tornam mais profundas do que estaríamos inicialmente dispostos a admitir.

O que a estética naturalizada de viés não-reducionista de Goodman torna evidente é justamente a multiplicidade de maneiras de organização da realidade artística. Não há um único modo (mágico) de conceber a arte, não há um modo objetivo de categorizar as obras de arte senão enquanto "modelos de realidade convencionais" que são corretos ou incorretos em virtude das funções para as quais foram projetados. Neste sentido, Giulio Argan ${ }^{25}$ estava certo ao pensar que o artista tem o dever de demonstrar o modo como chegou a seus resultados. O artista deve oferecer o "mapa" de sua descoberta, mesmo que (contra Argan) não seja possível fazer "história da arte" unicamente através daquilo que poderíamos chamar de "história das imagens", já que as imagens sem os conceitos seriam absolutamente vazias. Todavia, os processos formais são repletos de conteúdo (significado) e eles são determinados pelo conjunto das atividades culturais convencionais.

A questão epistêmica subjacente na proposta de Goodman em Linguagens da Arte está situada em uma perspectiva "irrealista-construtivista-relativista", a qual está necessariamente vinculada à recusa do pressuposto ontológico tradicional de que há uma realidade estruturada independentemente de nossas capacidades cognitivas. Ainda que a consequência óbvia deste modelo seja a recusa de uma noção de "verdade" como a correspondência entre proposições e fatos, isso não implica que a cognição esteja desvinculada de nossas capacidades de oferecer razões objetivas para nossas alegações de conhecimento. O critério de aceitabilidade geral, como já mencionado, será a adequação do modelo em função dos objetivos para os quais o mesmo foi criado.

Outras questões metodológicas específicas parecem brotar do modelo estético de Goodman, em especial a questão de que a arte não é uma cópia da realidade, pois o artista não está e nem poderia estar isento das categorias convencionais de representação. O que o artista faz quando pinta um quadro não é a cópia de uma realidade, mas, antes, é a construção de um novo modelo de realidade. Isso nos permite

${ }^{24}$ GOODMAN, N. Linguagens da Arte. Lisboa: Gradiva, 2006, p. 271.

${ }^{25}$ ARGAN, G. Arte Moderna. São Paulo: Companhia das Letras, 1999.

\begin{tabular}{|c|c|c|c|c|c|}
\hline intuitio & $\begin{array}{c}\text { ISSN } \\
1983-4012\end{array}$ & Porto Alegre & Vol.8 $-\mathrm{N}^{\circ} .1$ & $\begin{array}{c}\text { Junho } \\
2015\end{array}$ & p.04-14 \\
\hline
\end{tabular}


dizer que a arte não imita a realidade, mas, pelo contrário, a arte constrói modelos de realidade. A estética não tem nada a ver com o "gosto", o "belo" e o "único", mas, antes, seu papel é mostrar o modo como a arte constrói modelos de realidade e se torna uma atividade cognitiva ${ }^{26}$.

Segundo Ernest Gombrich, “o olhar sempre chega atrasado ao trabalho, pois está sempre obcecado com seu próprio passado e com as velhas e novas insinuações do ouvido, do nariz, da língua, dos dedos, do coração e do cérebro",27 " "O 'olhar' não é um instrumento isolado e independente, mas, antes, o olhar é um membro diligente de um organismo complexo e caprichoso. Não só o modo como vê, mas também o que vê é regulado pela necessidade e preconceito" ${ }^{28}$. O olhar seleciona, rejeita, organiza, discrimina, associa, classifica, analisa, constrói novos modelos de realidade. Nada é efetivamente visto à olho nu. É por isso que Goodman afirma: "os mitos do olhar inocente e do dado absoluto são cúmplices perversos". Tais mitos surgem da ideia de que o conhecimento é o fruto de uma espécie de processamento de um material bruto que é recebido pelos sentidos, e, também, pela ideia de que este material pode ser descoberto seja através de rituais de purificação, seja através da análise metódica. Gombrich pensava que a forma como um artista vê um objeto e o representa na pintura depende e varia de acordo com sua própria experiência, prática, interesses e atitudes ${ }^{29}$.

Para concluir, convém notar que a estética naturalizada de viés não-reducionista de Nelson Goodman reestabelece potencialmente a conexão antiga e por vezes desgastada entre "arte" e "estética", pois não existe aparentemente um abismo intransponível entre ambos os domínios. A arte constrói modelos de realidade e a estética explica "como" a arte é suficientemente capaz de realizar essa tarefa. A posição de Goodman também parece promissora não apenas no que diz respeito a ressaltar o papel cognitivo da arte, mas, sobretudo, em evidenciar a importância dos sistemas simbólicos enquanto critérios de correção para as nossas práticas mais corriqueiras.

\section{Referências}

ARGAN, G. Arte Moderna. São Paulo: Companhia das Letras, 1992.

BAKER, G. P. and HACKER, P. M. S. Essays on the Philosophical Investigations. Chicago: The University of Chicago Press, 1980.

CABANNE, P. Marcel Duchamp: Engenheiro do Tempo Perdido. São Paulo: Perspectiva, 2002.

${ }^{26}$ CAUQUELIN, Anne. Arte Contemporânea. São Paulo: Martins Fontes, 2005, p. 120.

${ }^{27}$ GOMBRICH, E. Art and Illusion. New York: Phanteon Books, 1960. p. 297-298. A passagem também é citada por Goodman em GOODMAN, N. Linguagens da Arte. Lisboa: Gradiva, 2006, p. 39.

${ }^{28}$ GOODMAN, N. Linguagens da Arte. Lisboa: Gradiva, 2006, p. 39.

${ }^{29}$ GOMBRICH, E. H. Arte e Ilusão: Um Estudo da Psicologia da Representação Pictórica. São Paulo: Martins Fontes, 2007.

\begin{tabular}{|c|c|c|c|c|c|}
\hline intuitio & $\begin{array}{c}\text { ISSN } \\
1983-4012\end{array}$ & Porto Alegre & Vol.8 $-\mathrm{N}^{\circ} .1$ & $\begin{array}{c}\text { Junho } \\
2015\end{array}$ & p.04-14 \\
\hline
\end{tabular}


CAUQUELIN, Anne. Arte Contemporânea: Uma Introdução. São Paulo: Martins Fontes, 2005.

CELA-CONDE, C. Activation of the prefontral cortex in the human visual aesthetic perception. New York: PNAS, 2004.

COUCHOT, E. La Nature de l'art : Ce que les sciences cognitives nous révèlent sur le plaisir esthétique. Paris: Hermann, 2012.

DANTO, A. Après la fin de l'art. Paris: Seuil, 1996.

. La tranfiguration du banal. Paris: Seuil, 1989.

. The abuse of beauty: aesthetics and the concept of art. Chicago: Carus, 2006.

DUCHAMP, M. Duchamp du Signe, reed. Paris: Flammarion, 1991.

GASSER, G. How Successful is Naturalism? Heusenstamm: Ontos Verlag, 2007.

GOMBRICH, E. H. Arte e Ilusão. São Paulo: Martins Fontes, 2007.

GOMBRICH, E. Art and Illusion. New York: Phanteon Books, 1960.

GOMBRICH, E.H. The sense of order: a study in the psychology of decorative art. London: Phaidon, 1984

GOODMAN, N. Linguagens da Arte. Lisboa: Gradiva, 2006.

GREEMBERG, C. Arte e Cultura. São Paulo: Ática, 2002.

HACKER, P.M.S. Insight and Illusion: Themes in the Philosophy of Wittgenstein. Oxford: Clarendon Press, 1986.

KENNY, A. Wittgenstein. Oxford: Blackwell Publishing, 2006. http://dx.doi.org/10.1002/9780470776643

KOSUTH, J. A Arte Depois da Filosofia. In. Escritos de Artistas. Rio de Janeiro: Jorge Zahar Editor, 2006.

JUDD, D. Objetos Específicos. In. Escritos de Artistas. Rio de Janeiro: Jorge Zahar Editor, 2006.

LEWIS, D. Convention: a Philosophical Study. Oxford: Blackwell, 2002. http://dx.doi.org/10.1002/9780470693711

. Scorekeeping in a Language Game. Journal of Philosophical Logic, 1979.

LEWITT, S. Parágrafos Sobre Arte Conceitual. In. Escritos de Artistas. Rio de Janeiro: Jorge Zahar Editor, 2006.

MCGINN, C. Wittgenstein on Meaning: An Interpretation and Evaluation. Aristotelian Society Series, Oxford: Blackwell, 1984.

MEDINA, J. Wittgenstein's Social Naturalism. In: The Third Wittgenstein. Burlington: Ashgate, 2004.

MILLIKAN, R. Language a Biological Model. Oxford: Oxford University Press, 2005. http://dx.doi.org/10.1093/0199284768.001.0001 . White Queen Psychology and Other Essays for Alice. Cambridge: MIT Press, 1995.

ONIANS, John. Neuroarthistory: from Aristotele and Pliny to Baxandall and Zeki. London: Yale, 2007.

PUTNAM, H. The Colapse of the Fact/Value Dichotomy and Others Essays. New York: Harvard University Press, 2004.

QUINE, W.V. The Two Dogmas of Empiricism. New York: The Philosophical Review 60, 1951 (20-43). http://dx.doi.org/10.2307/2181906

SANTAELLA, L. Cultura das Mídias. São Paulo: Razão Social, 1992.

SEARLE, J. Consciência e Linguagem. São Paulo: Martins Fontes, 2010

STRAWSON, P. Ceticismo e Naturalismo: Algumas Variedades. São Leopoldo: Unisinos, 2008

STROUD, B. Philosophers: Past and Present. New York: Oxford University Press, 2011. http://dx.doi.org/10.1093/acprof:oso/9780199608591.001.0001

WITTGENSTEIN, L. On Certainty. Oxford: Basil Blackwell, 1972. . Philosophical Investigations. Oxford: Basil Blackwell, 2009.

WRIGHT, C. Rule-Following, Meaning and Constructivism. Cambridge: Harvard University Press, 2001.

ZEKI, S. A vision of the brain. London: Blackwell, 1993.

ZEKI, S. Inner Vision: An Exploration of Art and the Brain. Oxford: Oxford University Press, 1999.

\begin{tabular}{|c|c|c|c|c|c|}
\hline intuitio & $\begin{array}{c}\text { ISSN } \\
1983-4012\end{array}$ & Porto Alegre & Vol.8 $-\mathrm{N}^{\circ} .1$ & $\begin{array}{c}\text { Junho } \\
2015\end{array}$ & p.04-14 \\
\hline
\end{tabular}

